\title{
Evaluation of Knowledge of Restorative Dental Staff about Personal Protective Equipments at Selected Dental Clinics, Saudi Arabia
}

\author{
Dr. Nasser Tayi Al-Mutairi ${ }^{1}$, Dr. Hatem Shabbab Almukhalfi ${ }^{2}$ \\ ${ }^{1}$ Dental Resident, Armed Forces Hospital, Najran \\ ${ }^{2}$ Dental Resident, Ministry of Health, Alqassim
}

\begin{abstract}
Background: Knowledge of Restorative Dental Staff about Personal Protective Equipments of Personnel Protective Equipments require to be highly valued and practices by all the health care practitioners, despite the fact that decisive staff development in the prevention of spread infectious diseases. Objective: To Evaluation of Knowledge of Restorative Dental Staff about Personal Protective Equipments among restorative dental staff at the Selected Dental Clinics-Saudi Arabia. Method: A cross-sectional survey was conducted at the Selected Dental Clinics-Saudi Arabia. . Tool was consists of 16 items self-administered questionnaire was provided to 200 restorative staff in the research setting based on their area of their specialties to assess their level of evaluation of Knowledge of Restorative Dental Staff about Personal Protective Equipments. Results: The findings of the current study showed than more than two third ((91.5\%)* of the respondents were very knowledgeable of Personnel Protective Equipments with statistically significantly difference in relation to the aspect of knowledge about (PPE).Moreover, it was found that Female Dental Restorative staff' ha d higher level of knowledgeable of Personnel Protective Equipments(86.5\%)than males (43.3\%). Furthermore, majority of the participants (87.5\%) replied that they were adequacy of protective equipments within the current research setting. Majority of participants (80\%) reported that they were positively in relation to value of adherence towards personnel protective equipments. Conclusions: The current study results revealed that there were a high levels of knowledge among restorative staff' towards Personal Protective Equipments within the study setting.
\end{abstract}

Keywords: Restorative staff; Knowledge; Awareness; Value \& Personnel Protective Equipments (PPE)

\section{Introduction}

Personnel Protective Equipments are meant to reduce the risk of transmission of blood borne pathogens from its sources. They are the basic level of infection control precautions which are to be used, as a minimum, in the care of all patients. (Muller \& McGeer , 2006). According to National Communicable Disease Center, Personnel Protective Equipments is designed to prevent the transmission of blood borne diseases such as human immune deficiency virus, hepatitis B, and other blood borne pathogens when first aid or health care is provided. Under Universal Precautions, blood and certain body fluids of all patients are considered potentially infectious.

Personnel Protective Equipments were initially developed in 1987 by the Centers for Disease Control and Prevention in the United States and in 1989 by the Bureau of Communicable Disease Epidemiology in Canada. The Precautions include Specific recommendations for use of gloves, gowns, masks, and protective eyewear when contact with blood or body secretions containing blood is anticipated. (Christian, et al., 2004)

Health care workers in particular restorative staff' is at risk of acquiring infection through professional exposure to infectious diseases. The minority studies have reported on restorative staff' adherence towards Personnel Protective Equipments and reported lack of adequate practices in relation to compliance towards the personnel protective equipments. (Peiris, et al., 2003).
Disclosure to particular health hazards are expected to influence definite high-risk for all the health care providers. All the health care workers especially the medical staff who are working in surgical units and Operation Theater are more required to have a reason of a better understanding in adherence with PPE usage which is significant as it provides an assessment of the efficacy of accessible preventative strategies. This could then assist to recognize the preventive variables which are likely to improve the compliance and decrease the risk of infection transmission. Then, it is possible to integrate these preventative approaches into the strategies of health care setting. (Loeb, et al., 2004 \& Ofner, et al., 2003)

Personnel Protective Equipments is the only approach so that all these infections could be prevented. Inadequate experience of restorative staff in performing invasive procedures, they are at particular risk of exposure to bloodborne pathogens (Chopra, et al., 2008). Restorative staff' should have reasonable knowledge and performance in relation to adherence to personnel protective equipments. Additionally, Low \& McGeer (2003), reported that dedicated training must be conducted before a restorative staff caring for any patient procedure particularly the ones concerning sharp devices. Physicians' compliance towards the personnel protective equipments has been reported to be with low rate. (Spring, 2007).

Hazards caused by non adherence to Personnel Protective Equipments by the health care providers, statistics reported 


\section{International Journal of Science and Research (IJSR) \\ ISSN (Online): 2319-7064 \\ Index Copernicus Value (2015): 78.96 Impact Factor (2015): 6.391}

by the Central Register of Occupational Diseases in Poland indicates that among 314 new cases of occupational diseases in HCWs in $2005, \mathrm{HBV}$ and $\mathrm{HCV}$ represented $42.6 \%$ of all cases.9 Despite the substantial reduction in HBV infection since vaccination was introduced in 1989, the incidence of HCV hepatitis in Poland is still on the increase in this occupational group. . Chaovavanich, et al., (2004) \& Siegel, et al., (2007).

Personnel Protective Equipments consciousness education has not been prominent among health care workers especially the category of restorative staff, particularly in developing countries. To the best of our knowledge and standardized practices with PPE among restorative staff. We, therefore, conducted this study to assess the levels of knowledge towards Personnel Protective Equipments among restorative dental staff during their duties at the Selected Dental Clinics, Saudi Arabia.

\section{Participants and Methods}

The participants were selected from the restorative staff at selected dental clinics. After signing an informed written consent form, the questionnaire was given to each participant. Before administration of the questionnaire, the purpose of the study was explained to each respondent and confidentiality of the information assured.

The research was carried out the authors who were appropriately trained in administering the informed consent and the self-report questionnaire to the health care workers. In this cross-sectional study, a structured questionnaire prepared by the authors, was administered to the participants. 16-itemes self-administered structured questionnaire about knowledge and awareness of Personnel Protective Equipments in the health care system was devised de novo and tested. It included a full range of response options, designed to identify the dental restoratives' level of knowledge towards Personnel Protective Equipments in the selected setting. Prior to distribution of the questionnaire, a pilot study was done on a selective group of health care workers who were asked to fill out the questionnaire and

return it back with their comments and criticism. Minor changes were then made to the final instrument.

The initial part of the questionnaire consisted of demographic information such as occupation, age, gender, and the marital status. The second part of the questionnaire comprised of questions regarding their knowledge dental restoratives' level of knowledge towards Personnel Protective Equipments in the selected setting.. This part also assessed awareness of policies regarding universal precautions, availability of protective equipments and measures how they value the use of protective equipments. It took approximately 15 minutes to complete each questionnaire.

The level of knowledge towards Personnel Protective Equipments by examining questions about: use of protective barriers such as gloves and gown, mask and protective goggles. A score of 4 " was assigned for a correct answer and - " for an incorrect answer. A health care worker who obtained a total score of 5 " was considered very knowledgeable;" -4 or 3 " -somewhat knowledgeable;" and 4 or 0 " not knowledgeable."

The personal protective equipments required by the health care worker include N95 mask, surgical mask, paper mask, protective goggles, gowns, gloves, and hair cover, among other equipments. These vary depending on the duty performed by the health care provider. If less than half of the personal protective equipment identified by the particular health care worker was provided, then provision was considered inadequate." If more than half of the protective equipment identified by the participants was provided, then provision was considered adequate."

The data were coded and analyzed by SPSS $^{\circledR}$ for Windows ${ }^{\circledR}$ ver. 12.0. Strict confidentiality was maintained. All the data were stored in computers at a secured location, with access provided only to the researchers involved in the study. The $\chi^{2}$ test was used to test association between categorical variables. A $\mathrm{p}$ value $<0.05$ (two-tailed) was considered statistically significant

\section{Results}

Table 1: Percentage of the level of Knowledge towards Personnel Protective Equipments Knowledge of Restorative Dental Staff Toward Personnel Protective Equipments, N (\%) Variable

\begin{tabular}{|l|l|l|l|}
\hline \multicolumn{4}{|l|}{ Knowledge of Restorative Dental Staff Toward Personnel Protective Equipments, N (\%) Variable } \\
\hline \multicolumn{4}{|l|}{ Not } \\
\hline Level of Knowledge Personnel Protective Equipment*
\end{tabular}

The level of awareness of Personnel Protective Equipments was significantly associated with many variables (Table .1).
The findings of the current study showed than more than two third $((91.5 \%) *$ of the respondents were very knowledgeable

\section{Volume 6 Issue 1, January 2017




\section{International Journal of Science and Research (IJSR) \\ ISSN (Online): 2319-7064 \\ Index Copernicus Value (2015): 78.96 | Impact Factor (2015): 6.391}

of Personnel Protective Equipments with statistically significantly difference in relation to the aspect of knowledge about (PPE).Moreover, it was found that Female Dental Restorative staff' had higher level of knowledgeable of Personnel Protective Equipments(86.5\%)than males $(43.3 \%)$. Furthermore, majority of the participants $(87.5 \%)$ replied that they were adequacy of protective equipments within the current research setting. Majority of participants $(80 \%)$ reported that they were positively in relation to value of adherence towards personnel protective equipments.

\section{Discussion}

This study showed that knowledge towards Personnel Protective Equipments among dental staff with restorative specialty showed that the level of awareness of Personnel Protective Equipments was significantly associated with many variables (Table.1). The findings of the current study showed than more than two third $((91.5 \%) *$ of the respondents were very knowledgeable of Personnel Protective Equipments with statistically significantly difference in relation to the aspect of knowledge about (PPE).Moreover, it was found that Female Dental Restorative staff' had higher level of knowledgeable of Personnel Protective Equipments(86.5\%)than males $(43.3 \%)$. Furthermore, majority of the participants $(87.5 \%)$ replied that they were adequacy of protective equipments within the current research setting. Majority of participants $(80 \%)$ reported that they were positively in relation to value of adherence towards personnel protective equipments.

Our survey found gaps in knowledge and adherence with recommended PPE use for influenza control across all types of dental staff with restorative specialty. This multi professional survey had a high overall response rate $(91.5 \%)$ and included respondents at the study setting. Significant variability in adherence was seen across the participants' knowledge toward the use of PPE. Conviction that PPE adherence was inconvenient was associated with decreased odds of self-reported high adherence. However, perception that a supervisor would reprimand non adherence significantly increased the odds of self-reported adherence.

Despite the fact that infection prevention and control practices can significantly improve patient outcomes at dental clinics adherence with these practices is generally high. In our survey of dental staff with restorative specialty, majority of the participants $(87.5 \%)$ replied that they were adequacy of protective equipments within the current research setting. Majority of participants $(80 \%)$ reported that they were positively in relation to value of adherence towards personnel protective equipments.

This self-reported adherence rate likely overestimates actual adherence. Henry et al, (2012) demonstrated that point estimates of self-reported adherence with all barrier precautions with the exception of gloves. Furthermore, the current study findings is consistent wth the reported results of the study carried out by, O'Boyle et al.,(2011) found that the correlation between reported and observed adherence with hand-washing recommendations among dentists was quite low $(r-.22)$. To overcome this overestimation, respondent reports regarding their colleagues adherence with expected practices have been used as a surrogate measure for actual adherence .toward PPE. Using this measure, we would estimate that adherence in our study is approximately $47 \%$. The fact that $(80 \%)$ of respondents felt they could improve their use of PPE confirms that they were aware that their adherence is suboptimal.

Little is known about how HCWs are currently using recommended barrier precautions to prevent spread of influenza and other respiratory viruses, or the factors that influence adherence. Identified influences on adherence to best practice guidelines have included knowledge, attitude, belief, and behavioral factors Predictors of PPE use Knowledge of correct PPE, age, and race were not significantly associated with reported PPE adherence in simple logistic regression (Table 1). Professional role, marital status, and specific beliefs about PPE use and efficacy were found to be significant predictors of high levels of adherence with PPE in both simple and multivariable logistic regression analyses.

Eighty percent of respondents reported a belief that PPE use would protect them and their patients, respectively, from getting influenza. Although this belief is plausible, given Centers for Disease Control and Prevention recommendations for PPE use, as we have mentioned, it is not supported by evidence from randomized clinical trials. Further, neither did this belief seem to influence behavior nor did it translate to similarly high levels of knowledge regarding recommendations. In fact, a large proportion of our respondents also demonstrated important knowledge gaps. This current study findings s congruent with the results carried out by Sandrock \& Stollenwerk (2008) , who reported that , more than $75 \%$ of respondents were unable to identify the group of precautions expected to confer appropriate protection from infection transmission of influenza. This knowledge gap suggests that some dentists may be unaware that they are inadequately protecting themselves and their patients. At least half of our respondents reported that complying with recommended PPE was inconvenient. Inconvenience, in turn, was predictive of poorer adherence.

\section{Acknowledgements}

Appreciation is hereby extended to all the participants for assisting with the statistical analysis of the data.

\section{Conflicts of Interest}

None declared.

\section{References}

[1] Sandrock C, Stollenwerk N: Acute febrile respiratory illness in the ICU: Reducing disease transmission. Chest 2008; 133:1221-1231 


\section{International Journal of Science and Research (IJSR) \\ ISSN (Online): 2319-7064 \\ Index Copernicus Value (2015): 78.96 Impact Factor (2015): 6.391}

[2] Muller MP, McGeer A: Febrile respiratory illness in the intensive care unit setting: An infection control perspective. Curr Opin Crit Care 2006; 12:37-42

[3] Christian MD, Loutfy M, McDonald LC, et al: Possible SARS coronavirus transmission during cardiopulmonary resuscitation. Emerg Infect Dis 2004; 10:287-293

[4] Fowler RA, Guest CB, Lapinsky SE, et al: Transmission of severe acute respiratory syndrome during intubation and mechanical ventilation. Am J Respir Crit Care Med 2004; 169:1198-1202

[5] Peiris JS, Chu CM, Cheng VC, et al: Clinical progression and viral load in a community outbreak of coronavirus-associated SARS pneumonia: A prospective study. Lancet 2003; 361:1767-1772

[6] Loeb M, McGeer A, Henry B, et al: SARS among critical care nurses, Toronto. Emerg Infect Dis 2004; 10:251-255

[7] Ofner M, Lem M, Sarwal S, et al: Cluster of severe acute respiratory syndrome cases among protected health-care workers - Toronto, Canada, April 2003. JAMA 2003; 289:2788 -2789; reprinted from MMWR Morb Mortal Wkly Rep 2003; 52: 433-436

[8] Karanfil LV, Conlon M, Lykens K, et al: Reducing the rate of nosocomially transmitted respiratory syncytial virus. Am J Infect Control 1999; 27:91-96

[9] Macartney KK, Gorelick MH, Manning ML, et al: Nosocomial respiratory syncytial virus infections: The cost-effectiveness and costbenefit of infection control. Pediatrics 2000; 106:520-526

[10] Spring. F-Vol. 1: The SARS Commission Executive Summary. Available at: http://www.sarscommission.ca/report/index.html. Accessed June 17, 2007

[11] Low DE, McGeer A: SARS-One year later. $N$ Engl J Med 2003; 349:2381-2382

[12] Chaovavanich A, Wongsawat J, Dowell SF, et al: Early containment of severe acute respiratory syndrome (SARS); experience from Bamrasnaradura Institute, Thailand. J Med Assoc Thai 2004; 87:1182-1187

[13] Booth TF, Kournikakis B, Bastien N, et al: Detection of airborne severe acute respiratory syndrome (SARS) coronavirus and environmental contamination in SARS outbreak units. J Infect Dis 2005; 191:1472-1477

[14] Cabana MD, Rand CS, Powe NR, et al: Why don't physicians follow clinical practice guidelines? A framework for improvement. JAMA 1999; 282:14581465

[15] Siegel JD, Rhinehart E, Jackson M, et al; Healthcare Infection Control Practices Advisory Committee. 2007 Guideline for Isolation Precautions: Preventing Transmission of Infectious Agents in Healthcare Settings. Available at: http://www.cdc.gov/

[16] ncidod/dhqp/gl_isolation.html. Accessed June 27, 2007

[17] Pittet D, Simon A, Hugonnet S, et al: Hand hygiene among physicians: Performance, beliefs, and perceptions. Ann Intern Med 2004; 141:1-8

[18] O'Boyle CA, Henly SJ, Larson E: Understanding adherence to hand hygiene recommendations: The theory of planned behavior. Am J Infect Control 2001; 29:352-360

[19] Sax H, Uckay I, Richet H, et al: Determinants of good adherence to hand hygiene among healthcare workers who have extensive exposure to hand hygiene campaigns. Infect Control Hosp Epidemiol 2007; 28:1267-1274

[20]Berhe M, Edmond MB, Bearman GM: Practices and an assessment of healthcare workers' perceptions of compliance with infection control knowledge of nosocomial infections. Am J Infect Control 2005; 33:55-57

[21] Hamilton LC: Statistics with Stata, updated for version 9. Belmont, Thomson-Brooks/ Cole, 2006

[22] Intercooled Stata 9.2. College Station, TX, StataCorp LP, 2005

[23]Daugherty EL, Rand CS, Speck KA, et al: Sociodemographic and Professional Factors Influencing Influenza Vaccination Among Healthcare Workers (HCWs) at a Large Urban University Hospital _Abstracts Issue_. Am J Respir Crit Care Med 2007; 175

[24] Doebbeling BN, Stanley GL, Sheetz CT, et al: Comparative efficacy of alternative handwashing agents in reducing nosocomial infections in intensive care units. N Engl J Med 1992; 327:88-93 